\title{
Cue set size effects: Sampling activated associates or cross-target interference?
}

\author{
DOUGLAS L. NELSON \\ University of South Florida, Tampa, Florida \\ THOMAS A. SCHREIBER \\ University of Kansas, Lawrence, Kansas \\ and \\ JIE XU \\ University of South Florida, Tampa, Florida
}

\begin{abstract}
Previous findings indicate that test cues linked to more associates (more knowledge) produce lower levels of recall than cues with fewer associates. One hypothesis attributes this effect to cross-target interference arising during retrieval on the assumption that cues with more associates are more likely to be indirectly connected to studied words other than the target. Another attributes the effect to sampling associates of the cue on the assumption that the probability of sampling the target declines as more associates are activated. Findings from four experiments showed that recall varied with cue set size, and, more importantly, that cue set size affected recall independently of the interference produced by cross-target connections. These results were interpreted as supporting a model that attributes cue set size effects to sampling processes associated with the intersection of the test cue and its associates with the target and its associates.
\end{abstract}

In everyday life we often learn to connect more than a single fact to the same stimulus. For example, most of us know several people named Jim whose last names are different, and we may know many facts about each Jim we know. Such information is acquired in the natural course of human affairs and, although the retrieval of the correct bit of knowledge seems direct under most circumstances, retrieval is sometimes slow, stumbling, and it sometimes fails altogether. Researchers have studied this phenomenon for 100 years using the paradigms of classical interference theory (for reviews, see Crowder, 1976; Underwood, 1983). These paradigms require subjects in an experimental condition to associate two different responses (e.g., Martin, 1971) or two or more facts (Anderson, 1983) to the same stimulus, whereas controls associate their responses to different stimuli. Under such circumstances, experimental subjects are generally less successful than controls during recall, presumably because the responses compete and interfere with each other during retrieval (McGeoch, 1942).

The general purpose of the present paper is to study interference in a paradigm that relies on prior knowledge to produce the competition. Subjects study a single list of

This research was supported by Mental Health Grant 16360 from the National Institute of Mental Health to D.L.N. Our special thanks go to Todd Leibert for his help in building the lists and collecting the data for Experiment 2, and to Cathy McEvoy for her comments on an earlier draft of the paper. Correspondence should be addressed to D. L. Nelson, Department of Psychology, University of South Florida, Tampa, FL 33620-8200 (e-mail:nelson@luna.cas.usf.edu). words and are then asked to use associatively related items as recall cues; for example, if the word PAPER is studied, its recall might be prompted by the cue CARDBOARD. This paradigm forms what is called an associative cuing task. One of the basic findings in this task is that recall is less likely to be successful when the test cue is connected to many associatively related words than when it is connected to only a few such words. In general, the more words connected to a given cue, the less the chances are of recovering one of them that has been recently studied. This phenomenon is called the cue set size effect, and it has been found for a variety of different types of cues, including meaningfully related words, names of taxonomic categories, and various types of word stems (for a review, see Nelson, Schreiber, \& McEvoy, 1992). Such effects cannot be attributed to guessing because guessing is controlled in such experiments by holding constant the strength of the connection from the test cue to the targeted studied word. In the absence of a study trial, the probability of recalling the target is the same for test cues having large and small sets. Furthermore, manipulations of guessing instructions appear to have no effect on the magnitude of this effect. Subjects who are required to guess recall more words than subjects who are forbidden, but the cue set size effect is the same regardless of the instructions. Finally, cue set size effects do not appear to be influenced by how well the targeted study words have been encoded. Subjects who have rated the study words for concreteness recall more words than those who have named their vowels, but the magnitude of the cue set size effect remains essentially unchanged. 
Cue set size effects are important because such effects indicate that the associates of the test cues can play an important role in episodic memory tasks. In contrast to classical studies on interference, in which the competing items are acquired in the task, words that are never presented during the task interfere with the recall of a word that has been presented. Such a result suggests that the cued recall of a recently studied word is influenced by what is generally known about the test cue as a result of prior learning outside of the laboratory. Test cues define sets of related items in memory and other nonpresented members of the set apparently interfere with the retrieval of one of its recently experienced members.

The present paper focuses on explanations for cue set size effects. PIER $2^{1}$ was designed to explain these and other effects related to the associates of both studied words and test cues. The model is composed of assumptions concerning encoding and retrieval (Nelson, McKinney, Gee, \& Janczura, 1998). Briefly, the encoding of a familiar word produces two representations, one involving the automatic parallel activation of the associates of a list word and one involving conscious processing activities carried out during presentation. The automatic activation component serves comprehension by providing immediate access to prior knowledge about the word, and it produces an implicit representation that consists of an activated representation of the target and its associates. The conscious component reflects what subjects do to meet task demands (e.g., rehearsal) and produces an explicit or episodic representation best described as a list memory that incorporates contextual information linked to the episode.

On the retrieval side, the presentation of cues under instructions to use them to recall list words sets up two retrieval structures, each of which can contribute independently to recall. One structure is used to compute the intersection of the test cue with the explicit representations of the list words, and the model borrows SAM to capture this process (Gillund \& Shiffrin, 1984; Raaijmakers \& Shiffrin, 1981). The associates of the test cue play no role in computing this intersection. The other structure is designed to recover the target as a residual implicit activation. PIER 2 assumes that the likelihood of retrieving the target from this structure is determined by the intersection of the test cue and its associates with the target and its associates. As when the target is presented during encoding, the presentation of the test cue activates its associates, and cue set size effects arise because some of the associates linked to the cue are not directly linked with the target and compete for its selection. For example, presenting CARDBOARD as a test cue activates box, paper, blackboard, brown, and so on, and the activation of these associates reduces the probability of sampling PAPER, the studied target. The probability of sampling the target in this activation is determined by the net strength of the cue-to-target relationship as an implicit activation relative to the noise produced by competing associates. Cues with larger sets of associates theoretically generate more noise than those with smaller sets and are less likely to be successful. This point is important because the purpose of this article is to evaluate an alternative explanation for cue set size effects.

What we will call the cross-target hypothesis was suggested by Humphreys, Wiles, and Dennis (1994) in describing their general computational level theory concerning the nature of memory tasks. This hypothesis was not a central feature of their model, and it deviates from their earlier account of set size effects, which is similar to that of PIER 2 (Humphreys, Bain, \& Pike, 1989). However, this interesting hypothesis attributes cue set size effects to connections between the test cue and its associates with words appearing in the study list. According to this idea, and unlike PIER 2, both the test cue and its associates are incorporated into the intersection with the list words.

The cross-target hypothesis assumes that test cues that activate larger sets of associates should be more likely to fail because, on a probabilistic basis, they would be more likely to be connected to other words in the study list. Test cues with larger sets of natural associates should increase the number of list items appearing in the intersection because the likelihood of unintended connections is simply greater when larger numbers of associates are involved. For example, CARDBOARD may fail as a test cue because it is related to the words BAG, TREE, MARBLE, and FLY, which could appear in the study list along with the word PAPER. CARDBOARD is presumably not directly connected to any of these words because it fails to produce any of them in free association or, at the least, the direct connections are too weak to be detected by this procedure. However, CARDBOARD does share indirect connections with these words. The CARDBOARD-BAG pairing shares three common associates and two mediators. Each word in this pairing produces box, paper, and brown as associates, and therefore the two words are connected indirectly because they share connections to some of the same words. In addition, they share two mediators, CARDBOARD-to-paper-toBAG and CARDBOARD-to-brown-to-BAG. The CARDBOARDTREE pairing involves two mediated connections, and so on. Although CARDBOARD is strongly related to PAPER in terms of both direct and indirect connections, it is indirectly connected to other words appearing in the study list.

We first attempted to validate the feasibility of the cross-target hypothesis by calculating the number of cross-target connections appearing in the lists used in 20 experiments with the associative cuing task in our lab. Controlling such connections is particularly important for work with this task and, like others before us, we had relied on our own relatedness judgments to eliminate items with such connections during the list construction process. However, several years ago, T.A.S. developed a computer program that relied on an associative database of thousands of words that could find and report both direct (forward and backward) and indirect (converging and mediating) connections in any set of words. The main surprising result of this effort was that many indirect connections were detected by the program that went un- 
detected by our relatedness judgments. Despite intense efforts to control relatedness along with frequency, concreteness, and other word attributes, we failed to control a potentially important variable. The analysis of the 20 cuing experiments produced usable values for 1,699 cuetarget pairs, and we found that each test cue was indirectly connected to an average of $3.15(S D=2.03)$ other target words appearing in the list (range $=1-10$ ). Importantly, the correlation between number of cross-target connections and cue set size was $r=.50$. Hence, there appears to be a sizable relationship between these two measures, with large-set cues showing more cross-target connections than small-set cues.

What is just as important, related research on indirect connections in the associative cuing task has recently shown that both converging and mediating connections between the test cue and its intended target facilitate recall (Nelson, McKinney, et al., 1998). The beneficial effects of indirect connections appear to be limited to twostep links, and they are more apparent when direct connection strength is weak than when it is strong (Nelson, Bennett, \& Leibert, 1997). Nevertheless, the important point is that previously unrecognized and fairly weak indirect connections between the test cue and its target benefited recall, and these findings made the cross-target explanation for cue set size effects all the more tenable. If indirect connections can benefit cued recall when they link the cue to the target, then it seemed reasonable to assume that they could interfere when they were linked to other potential targets in the list. The question, however, is not whether cross-target connections will interfere but whether the presence of such connections can explain cue set size effects or whether such connections produce interference independently of set size.

These correlation and cuing findings had threatening implications for the PIER 2 explanation for set size effects, which had piqued our interest, but the findings had broader implications as well. Both explanations of cue set size effects rely on computing intersections, but the hypothetical content of these intersections is different. According to PIER 2, cue set size effects are the result of computing the intersection between the test cue and its associates with the target and its associates as an implicit representation. In contrast, according to the cross-target hypothesis, such effects are caused by preexisting connections between the test cues and their associates with words appearing in the study list. The cross-target hypothesis attributes cue set size effects to competition engendered because some test cues are connected to more list words than others. The strong interpretation of this hypothesis is that the test cues must be related to list words other than the target for cue set size effects to occur. The broader issue is whether the interference that occurs in recalling a recent event must be attributed to links between the test cue and information encoded in the episode or whether such interference can arise solely as a result of preexisting knowledge activated by the cue. If the stronger version of the cross-target hypothesis is correct, it would seem reasonable to conclude that episodic context dominates cued recall. Alternatively, if cue set size and cross-target connections represent separate sources of interference, it would seem reasonable to conclude that episodic information and prior knowledge can contribute independently to performance. This issue is important because it goes to the heart of a long-standing issue regarding the role of prior knowledge in the performance of episodic memory tasks (see, e.g., Bahrick, 1970; Tulving \& Thomson, 1973; Underwood, 1983).

In Experiment 1, cue set size and cross-target interference were manipulated in an associative cuing task in which the target words were studied and the test cues were shown only during testing. Cue set size was small or large, and subjects studied a high or a low cross-target interference list. High cross-target interference was produced by including a specific competing target for critical test cues in the study list. In the high-interference condition, each test cue was strongly related to its designated target and it shared three indirect connections with another word appearing in the study list. Cross-target interference was low when the competing word was replaced by an unrelated item, or filler. For example, in the high-interference list, both PAPER and BAG appeared in the study list, with CARDBOARD presented as one of the test cues. As noted, this cue is directly and indirectly related to PAPER and indirectly related to BAG. In the low-interference list, PAPER was presented in the study list but BAG was not, with CARDBOARD still presented as one of the test cues. In this design, the same words were used as critical pairs in the highand low-interference lists.

The strengths of the cross-target connections were equated at each level of cue set size in the present experiments. This point is important because the cross-target hypothesis leads to the expectation that set size effects should not be found when the interference owing to crosstarget connections is the same for cues having small and large sets of associates. Although cross-target interference effects should be apparent, cue set 'size effects should not. In contrast, according to PIER 2, cue set size effects arise from the competition experienced in sampling the pool of items activated by the test cue, with cues having larger sets of associates producing more competition than those having smaller sets. This situation would not change in the presence of cross-target interference, and therefore the model predicts that cue set size effects should be equally apparent within each interference condition. Furthermore, if cross-target interference effects are present, PIER 2 can explain this result because both the interference item and the designated target are associated to the same test cue. The model computes two intersections, and one of them theoretically involves the test cue and the episodic representation of the list items. The purpose of Experiment 2 was to replicate the results of Experiment 1 with new materials. The purpose of Experiment 3 was to determine whether studying the cross-target pairs prior to studying the targets would influence the magnitude of the cue set size effect, and similarly, the aim of Experiment 4 
Table 1

Examples of Calculating Net Cue-to-Target Strength and

Net Cross-Target Strength With SANDWICH as the Test Cue, BREAD as the Designated Target, and HUNGER as the Cross-Target

Intersection bread sandwich food eat meat bologna peanut butter
Net Cue-to-Target Strength With SANDWICH as the Test Cue and BREAD as the Target

$\begin{array}{rlllllll} & (\mathrm{F}) & (\mathrm{B}) & (\mathrm{S}) & (\mathrm{S}) & (\mathrm{S}) & (\mathrm{M}) & (\mathrm{M}) \\ \text { BREAD } & 1.00 & .03 & .05 & .03 & .01 & .03 & .02 \\ \text { SANDWICH } & .07 & 1.00 & .21 & .06 & .02 & .05 & .03 \\ & \mathbf{S}\left(\mathbf{Q}_{j}, \mathbf{T}_{i}\right)= & \sum_{k}^{n} \mathbf{S}_{j k} \mathbf{S}_{i k}+\sum_{k}^{n} \mathbf{S}_{j k} \mathbf{S}_{k i}=S(\text { SANDWICH, BREAD }) \\ = & (.07 \times 1.00)+(1.00 \times .03)+(.21 \times .05)+(.06 \times .03) \\ & +(.02 \times .01)+(.05 \times .03)+(.03 \times .02)=.106\end{array}$

Net Cross-Target Strength With SANDWICH as the Test Cue and HUNGER as Cross-Target

\begin{tabular}{lccccccc} 
Intersection & hunger & sandwich & food & eat & hungry & food & eat \\
\hline & $(\mathrm{F})$ & $(\mathrm{B})$ & $(\mathrm{S})$ & $(\mathrm{S})$ & $(\mathrm{S})$ & $(\mathrm{M})$ & $(\mathrm{M})$ \\
HUNGER & 1.00 & 0.00 & .36 & .08 & .01 & .04 & .02 \\
SANDWICH & 0.00 & 1.00 & .21 & .06 & .04 & .21 & .06
\end{tabular}

$\mathbf{S}\left(\mathbf{Q}_{j}, \mathbf{T}_{i}\right)=\sum_{k}^{n} \mathbf{S}_{j k} \mathbf{S}_{i k}+\sum_{k}^{n} \mathbf{S}_{j k} \mathbf{S}_{k i}=S($ SANDWICH, HUNGER $)$

$=(0.00 \times 1.00)+(1.00 \times 0.00)+(.21 \times .36)+(.06 \times .08)$

$+(.06 \times .08)+(.04 \times .01)+(.21 \times .04)+(.06 \times .02)=.090$

Note- - F, forward strength; B, backward strength; $S$, shared associate strength; $M$, mediated strength. Self-strength is set to 1.00 .

was to determine whether direct connections among these pairs would affect the magnitude of these effects.

\section{EXPERIMENT 1}

\section{Method}

\section{Design and Subjects}

The design formed a $2 \times 2$ mixed-model factorial, with crosstarget interference (high, low) varied between subjects and with cue set size (small, large) varied within subjects. Fifty-six university students served in the experiment for extra course credit, with 28 assigned to each between-subjects condition.

\section{Materials}

The target words and test cues are presented in Appendix A for the two lists used in the experiment. Each list contains 24 target words and 24 test cues selected from word association norms (Nelson, McEvoy, \& Schreiber, 1998).

The norms ( $>5,000$ words) were collected by presenting words. to an average of 150 students who were asked to write down the first associated word that came to mind. The number of different words provided by 2 or more subjects was then used to estimate set size. The probability that any particular word was given was used to estimate cue-to-target (forward) and target-to-cue (backward) strength. Mediated strength for a given cue-target pair was determined by multiplying cue-to-mediator strength by mediator-to-target strength and summing the results when multiple mediators were involved. Similarly, shared associate strength was calculated by multiplying cue-to-shared associate strength by target-to-shared associate strength and then summing the results when there was more than a single shared associate. Net cue-to-target strength was then determined for each pair by using the following equation (see Nelson et al., 1997, for more details):

$$
\mathbf{S}\left(\mathbf{Q}_{j}, \mathbf{T}_{i}\right)=\sum_{k}^{n} \mathbf{S}_{j k} \mathbf{S}_{i k}+\sum_{k}^{n} \mathbf{S}_{j k} \mathbf{S}_{k i} .
$$

A numerical example is provided for this rule in the upper portion of Table 1, and as can be seen, the rule adds forward, backward, shared associate, and mediated strength on the assumption that the strength of the connection between any two words is best described as the sum of all of the direct and indirect two-step connections that link them to each other. Associates of either the cue or the target that are not involved in linking the words either directly or indirectly are not included in this calculation (i.e., arbitrary residual strengths are not assigned). This rule was used to calculate net cue-to-target strength for the designated target, the designated interference filler, and other study words appearing in each list.

The same designated targets were used in both the high- and the low-interference lists. The high-interference lists were constructed by selecting fillers that were presented as study words and that were indirectly related to their assigned critical cues. The low-interference lists were constructed from the high-interference lists by simply changing the fillers. These fillers were not related to critical cues, as in the previous high-interference lists. With this procedure, the primary difference between high- and low-interference lists was that the former contained a specific indirectly related target for each test cue and the latter did not. The advantage of this method was that it eliminated item selection effects because the critical target and its test cue were the same in the high- and low-interference lists. Because only the critical items were used in all subsequent analyses in this paper, the descriptive characteristics of the filler items have been omitted to conserve space, but it should be noted that the cues selected for the fillers also varied in cue set size.

Half of the cues for critical items had small meaning sets, averaging $7.40(S D=1.08)$ different associates per cue, and half had large meaning sets, averaging $21.25(S D=2.99)$ associates per cue. For these items, forward, backward, shared associate, and mediated strength averaged, respectively, $.17(S D=.08), .04(S D=.04), .03$ $(S D=.04)$, and $.04(S D=.06)$, and net cue-to-target strength averaged $.28(S D=.11)$. Although the same cues and targets were used in each interference condition, the norms were also used to equate other characteristics of these items as closely as possible across vari- 
ations in cue set size. The printed frequency (Kučera \& Francis, 1967) of the test cues averaged 85 per million words $(S D=106)$, their concreteness ratings on a $1-7$ scale averaged $5.12(S D=1.23)$, and each of their associates had an average of $1.56(S D=.76)$ connections to other associates in the set. Target set size averaged 16.29 associates $(S D=4.29)$, their printed frequency averaged 114 per million $(S D=160)$, their concreteness averaged $4.92(S D=1.42)$, and each of their associates was connected to an average 1.63 other associates in the set $(S D=.77)$. Put simply, the cues and targets were low to moderate in frequency, they were mostly concrete words, and their associates were about average in interconnectivity.

None of the test cues used for the critical designated targets had direct forward or backward connections to any of the other targets, as is usually the case when lists are constructed. However, in the highinterference condition, each cue was related to its filler in terms of indirect measures of association. For these items, shared associate strength averaged $.01(S D=.02)$ and mediated strength averaged $.01(S D=.005)$, for a net cross-target strength of $.02(S D=.004)$. Each of the critical cues had an average of $4.50(S D=1.35)$ connections with its competing target. Moreover, these cues also had indirect connections to $4.38(S D=2.36)$ other nondesignated targets appearing in the list, which added $.01(S D=.01)$ to cross-target strength. Hence, in the high-interference lists, each cue had an average of $8.42(S D=3.02)$ connections to other words appearing in the study list, and the summed net cross-target strength averaged $.03(S D=.03)$ overall. In contrast, in the low-interference lists, each of the critical cues had an average of 4.58 connections to other list words and a net cross-target strength average of $.01(S D=.02)$. Cross-target strength for the high- and low-interference lists was equivalent for nondesignated items, so the two conditions differed in cross-target strength only in terms of interference generated by the designated item.

The interference manipulation was relatively weak on average, differing by only $2 \%$ in the high- and low-interference conditions, but this weakness is a consequence of the research design. The requirement of no direct forward and backward cross-target connections was incorporated to simulate the typical lists used in cued recall experiments in which direct connections between cross-target pairs are eliminated during the list construction process. This requirement placed severe restrictions on the magnitude of net crosstarget strength. The cross-target items chosen represented the strongest items that we could find when the experiment was run. However, it should be noted that, despite the apparent weakness reflected in the averages, every critical cue showed greater cross-target strength when it appeared in the high-interference condition than when it appeared in the low-interference condition. This issue will be considered again at the end of Experiment 2 in the context of a regression analysis that pooled the data across both experiments.

\section{Procedure}

Subjects participated in individual sessions and received a single study test trial. All items were typed in uppercase letters and were presented on a Macintosh computer. Before the study phase, subjects were shown six names, one name at a time, and they were asked to read each one aloud as shown. The purpose of this task was to familiarize them with the apparatus and the presentation rate. During the study phase, subjects were shown one target at a time on the computer screen at a $3 \mathrm{sec}$ rate. They were asked to read each word aloud and to remember as many words as possible. During the test trial, the subjects were asked to read each cue word aloud before attempting target recall, and they were told to recall a list word that was meaningfully related to the test cue. This test trial was paced by subjects, with guessing allowed but not required. In each condition, the presentation orders of the items appearing during study and test were unsystematically randomized for every subject. Finally, although the filler items were not analyzed, cues for these items were presented during the test trial, and they were randomly intermixed with the cues for the critical items.

\section{Results}

The probabilities of correct recall under the highinterference condition were, respectively, .59 and .29 for cues having small and large associative sets. For the lowinterference condition, these probabilities were .64 and .41 . These values indicate that words in the highinterference list were $8 \%$ less likely to be remembered than words in the low-interference list, and that recall was more likely when cue set size was small than when it was large. The effect of cue set size $\left[F(1,54)=72.40, M S_{\mathrm{e}}=.03\right]$ was significant. However, the effect of cross-target interference $\left[F(1,54)=3.58, M S_{\mathrm{e}}=.05\right]$ approached but did not reach the criterion for significance, $p<.06$, and the interaction between cue set size and cross-target interference was unreliable $[F(1,54)=1.35]$. An analysis of the number of designated cross-target intrusions in the high-interference condition indicated that such intrusions were too rare to analyze statistically. When cue set size was small, there were no such intrusions, and when it was large, the probability of designated cross-target intrusion was .05.

\section{EXPERIMENT 2}

The findings of Experiment 1 are consistent with the conclusion that cue set size effects are not the result of a natural confounding between cue set size and indirect cross-target connections. When the strength of such connections was controlled, as in Experiment 1, cue set size effects remain apparent. There was, however, also a strong trend suggesting that even relatively weak cross-target connections impair recall, and this trend was apparent within each level of cue set size. Taken together, these results suggest that both larger cue set sizes and cross-target connections involving the test cues and other words appearing in the study list independently interfere with recalling the designated target.

The main purpose of Experiment 2 was to replicate these findings with new materials. Forward cue-to-target strength was reduced on the assumption that cross-target strength effects produced by indirect connections would be more apparent with weaker cues. Such is the case when indirect connection strength is varied between the cue and its designated target (Nelson et al., 1997). In addition, on the assumption that having to recall the filler items might influence their potential for interference, half of the subjects were given cues for both critical items and fillers during testing, as in Experiment 1, whereas the remaining half were only given cues related to the critical items.

\section{Method}

\section{Design and Subjects}

The design formed a $2 \times 2 \times 2$ mixed-model factorial. Crosstarget interference (high, low) and competitor cuing (yes, no) were varied between subjects and cue set size (small, large) was varied 
Table 2

Probability of Correct Recall of the Critical Items as a Function of Cross-Target Interference, Cue Set Size, and Whether the Fillers Were Cued or Not

\begin{tabular}{cccccc}
\hline & \multicolumn{2}{c}{ High Cross-Target Interference } & & \multicolumn{2}{c}{ Low Cross-Target Interference } \\
\cline { 2 - 3 } Cuing of Filler Targets & Small Cue Set Size & Large Cue Set Size & & Small Cue Set Size & Large Cue Set Size \\
Not cued & .53 & .31 & .54 & .33 \\
Cued & .43 & .22 & & .45 & .21 \\
\hline
\end{tabular}

within subjects. Eighty university students served in the experiment for extra course credit, with 20 assigned to each between-subjects condition.

\begin{abstract}
Materials
The 32 target words and their test cues for each list are presented in Appendix B. The same rules were used to construct these lists as before except that cues were selected for fillers appearing in the high- and low-interference conditions. Half of the test cues for critical items had small meaning sets, averaging $7.31(S D=.95)$ associates per cue, and half had large meaning sets, averaging 22.00 $(S D=2.56)$ associates per cue. For these items, forward, backward, shared associate, and mediated strength averaged, respectively, .05 $(S D=.03), .04(S D=.08), .06(S D=.11)$, and $.01(S D=.03)$, and net cue-to-target strength averaged $19(S D=.16)$. The norms were also used to equate other characteristics of the cues and targets. Test cues had an average frequency of 39 per million words $(S D=76)$, an average concreteness rating of $4.88(S D=1.38)$, and each associate was connected to an average of $1.84(S D=.51)$ other associates in the set. Target set size averaged 15.22 associates $(S D=5.64)$, frequency averaged 52 per million words $(S D=70)$, concreteness averaged $5.13(S D=1.30)$, and connectivity among the associates averaged $1.93(S D=.84)$.

As before, none of the test cues used for the critical designated targets had direct forward or backward connections to any of the other targets. In the high-interference condition, each cue was related to its filler in terms of indirect measures of association. For these items, shared associate strength averaged $.02(S D=.03)$ and mediated strength averaged $.004(S D=.004)$, for a net cross-target strength of $.02(S D=.03)$. Each of the critical cues had an average of $4.50(S D=1.52)$ connections with its competing target. Moreover, these cues also had indirect connections to 3.81 other nondesignated targets appearing in the list, which added $.01(S D=.01)$ to cross-target strength. Hence, in the high-interference lists, each cue had an average of 8.87 connections to other words appearing in the study list, and the summed net cross-target strength averaged $.03(S D=.03)$ overall. In contrast, in the low-interference lists, each of the critical cues had an average of 5.62 connections to other list words and a net cross-target strength average of .01 $(S D=.01)$. As in Experiment 1, cross-target strength for the high- and low-interference lists was equivalent for nondesignated items and, once again, the two conditions differed in cross-target strength only in terms of interference generated by the designated item. Despite attempts to increase the magnitude of the cross-strength manipulation, it was the same as in the initial experiment.
\end{abstract}

\section{Procedure}

The procedure was the same as that used in Experiment 1, including the use of the 3-sec presentation rate and intentional learning instructions, self-paced testing, and so on. The only difference was that for half of the subjects, test cues were presented only for the critical items. None of the cues for the filler items were ever presented. The other half of the subjects were presented with cues related to critical items and with cues related to the fillers. Such cues were included only to produce recall of the fillers, and the results associated with these cues were ignored in the analysis of the findings.

\section{Results and Discussion}

Probability of correct recall for each of the main conditions is shown in Table 2. As can be seen, the probability of cued recall for the critical items was higher when cues for the filler items were not presented (.43) than when they were presented (.33), and this difference was significant $\left[F(1,76)=11.48, M S_{\mathrm{e}}=.04\right]$. Furthermore, recall was considerably higher in each condition when cue set size was small (.49) than when it was large (.27), and this difference was also significant $[F(1,76)=83.91$, $\left.M S_{\mathrm{e}}=.023\right]$. The interaction between these two sources was unreliable $(F<1)$. More importantly, despite lowering the level of forward cue-to-target strength from the level used in Experiment 1, the probability of recall in the high-interference lists (.37) was essentially the same as the probability of recall in the low-interference lists (.38). Cross-target strength failed to have any discernible effects on recall overall and did not interact with any of the other variables (all $F \mathrm{~s}<1.00$ ).

A tabulation of the probabilities of producing the cross-target to the critical test cue indicated that these probabilities were greater than those found in the initial experiment. Nevertheless, the presence of many zero scores precluded meaningful statistical analyses. In the interference lists, the probabilities of producing the crosstarget instead of the designated target when the fillers were not cued were, respectively, .13 and .08 for small and large sets. The respective values when recall of the fillers was prompted by presenting directly related cues were .28 and .27. Given that the baseline probabilities of producing these associates in the absence of study was .03, these values are well above chance.

\section{Regression Analysis}

The critical cue-target pairs from the high-interference lists used in Experiments 1 and 2 were subjected to an item analysis, and the results were evaluated in a multiple regression analysis involving 176 pairings. Items from the competitor cuing conditions of Experiment 2 were entered separately for each condition. Three variables were entered in the main analysis, including net cue-to-target strength, cue set size, and cross-target strength summed over shared associates and mediated connections. The 
results showed that these variables were significantly related to probability of recall $[r=.59, F(3,172)=28.70$, $\left.M S_{\mathrm{e}}=.039\right]$. Net strength, cue set size, and summed crosstarget strength each contributed significantly to the relationship. The respective $t$ values (and the standardized beta coefficients) were $5.22(.35),-5.24(-.35)$, and -2.82 $(-.18)$. This pattern of results did not change appreciably when each component of net strength and cross-target strength was entered separately, nor did it change appreciably when the number of cross-target connections was entered in place of the summed strength measure. Hence, analyses at the item level indicate that recall varied with each manipulation. Although cross-target connections produced a small interference effect in the subject-based analysis in Experiment 1 and no effect in Experiment 2, such connections significantly disrupted performance at the item level according to the regression analyses.

We should also mention that the database of 20 experiments used to compute the unadjusted correlation between cue set size and number of cross-target connections described in the introduction was also used to run a regression analysis comparable to the one reported above. Cue set size was held constant in 18 of these experiments, and number of cross-target connections varied freely because we had not thought to look at such values before. Data from the present experiments were not included in this analysis, but the findings did not change appreciably. Net strength, cue set size, and number of cross-target connections were significantly related to probability of recall $\left[r=.48, F(3,1694)=168.20, M S_{\mathrm{e}}=.053\right]$. Net strength $[t=20.98(.48)]$ and set size $[t=-2.10(-.003)]$, were significantly related to probability of recall. Number of cross-target connections approached but did not reach significance $[t=-1.74(-.006), p<.08]$.

What is of most theoretical interest is that these regression analyses indicate that both cue set size and crosstarget connections tend to influence cued recall, with set size having a larger and more consistently significant influence than indirect cross-target connections. This finding is wholly consistent with the assumption that, despite the general correlation between these two variables, cue set size effects are not produced as a result of cross-target connections. The subject and the item analyses are in complete agreement on this point.

\section{EXPERIMENTS 3 AND 4}

The results of Experiments 1 and 2 indicated that cue set size effects were much in evidence and that the magnitude of these effects was essentially uninfluenced by the presence of cross-target connections in the list. This summary serves as a satisfactory conclusion for the main findings in the sense that cue set size effects as they have been obtained in past cuing experiments cannot be attributed to cross-target connections. Given that cues are not directly related to other targets in the study list, crosstarget connections arising through shared associates and mediated connections tend to be weak and, as a consequence, produce only small and sometimes unreliable amounts of interference. The interference that they do produce does not seem to detract in any obvious way from the influence arising when cues have larger as opposed to smaller sets of associates.

Despite the apparent soundness of this conclusion for the typical associative cuing experiment, a potentially nettlesome question remains to be settled. Would cue set size effects remain undisturbed if the cross-target connections were substantially stronger? PIER 2 predicts that cue set size effects will be apparent regardless of the presence of cross-target connections and no matter how strong they are. This prediction follows from the assumption that set size and cross-target interference effects arise independently from the computation of two different intersections: the cue and its associates with the target and its associates, and the cue with the list representation.

To test this prediction, subjects studied the cross-target pairs prior to studying the target list in the typical associative cuing experiment. Subjects in Experiment 3 studied either the high- or the low-interference fillers used in Experiment 1 prior to studying the target list. In other words, Experiment 3 replicated the initial experiment except subjects studied the cross-target pairs prior to participating in the cuing task. Subjects in Experiment 4 either did or did not study cross-target pairings that were directly rather than indirectly associated before studying the target words. There was no low-interference condition, as in the three previous experiments. Instead, the presence/ absence of interference was manipulated by whether or not cross-target pairings were studied prior to the target list. The cued recall test followed the target list and was expected to show interference effects due to the prior study of cross-target connections. However, the presence of such interference was not expected to influence the magnitude of the cue set size effect. Such a result would suggest that cue set size effects remain unaffected even when cross-target interference is more apparent during retrieval.

\section{Experiment 3}

\section{Method}

Design and Subjects. The design of Experiment 3 formed a $2 \times 2$ factorial with interference (high, low) manipulated between subjects and with cue set size (small, large) manipulated within subjects. Twenty-eight subjects participated in each between-subjects condition with 14 assigned to each list.

Materials and Procedure. Cross-target pairs were taken from either the high- or the low-interference lists used in Experiment 1. These pairs were presented prior to the target word study trial at a 3-sec rate, one pair at a time. Subjects were told to concentrate on the relationship between each pair of words and to remember as many as possible. As soon as the last pair was presented, subjects were told that a list of single words would now be shown on the screen and they should read each word aloud and remember as many of them as possible. These words consisted of the target words used in Experiment 1, and they were presented under the same conditions. The test instructions followed the presentation of the sec- 
ond list, and these instructions were similar to those of Experiment 1 except that subjects were told that the meaning cues would help them recall the words from the second list.

\section{Results}

The probabilities of correct recall in the highinterference list for cues having small and large sets of associates were .36 and .23 , respectively. In the lowinterference lists, these values were .57 and .37 . On average, recall was $17 \%$ lower in the high- than in the lowinterference lists, suggesting that studying the indirectly associated cross-target pairs interfered with recall. However, cue set size effects were clearly evident at each level of interference. An analysis of variance of these findings indicated that cross-target interference $[F(1,54)=18.89$, $\left.M S_{\mathrm{e}}=.05\right]$ and cue set size $\left[F(1,54)=26.81, M S_{\mathrm{e}}=.03\right]$ were significant sources of variance. The interaction between these two sources was not significant $[F(1,54)=$ 1.07].

\section{Experiment 4}

\section{Method}

Design and Subjects. The experimental design formed a $2 \times 2$ mixed-model factorial. Prior study of the cross-target pairs (yes, no) was manipulated between subjects, and cue set size (small, large) was manipulated within subjects. Fifty-six university students served in the experiment, with 28 assigned to each between-subjects condition.

Materials. The target words and test cues are presented in Appendix $\mathrm{C}$ for the two lists used in the experiment. The designated targets and their cues were identical to those used in Experiment 1. The fillers were changed so that each cue was directly and strongly related to its designated target but also directly and weakly related to one other word in the list. For example, the critical pairing SOCCERFOOTBALL was not changed, but its indirectly related cross-target pair STATUE-MARBLE was replaced with TOYS-PLAY, so that SOCCER was weakly but directly related to the cross-target word PLAY. When pooled over lists, net cue-to-target strength for the designated targets averaged .28, the same value as in Experiment 1, because the same items were used, and, of course, the values for cue set size were the same as well. For the new filler items, net cross-target strength averaged $.06(S D=.04)$, which contrasts with the value of .02 for Experiments 1 and 3. The forward, backward, shared, and mediated components for the present experiment were $.03(S D=$ $.03), .01(S D=.03), .01(S D=.02)$, and $.01(S D=.01)$, respectively. Net cross-target strength was greater in this experiment because of the presence of direct but weak forward and backward connections between the test cues and their competing fillers. Of course, the test cues also had indirect connections with other target words appearing in the study phase. In addition to the connection between each cue and its filler, each cue had an average of $5.08(S D=4.80)$ indirect connections to an average of $3.21(S D=2.52)$ other words in the study list. When this additional source of interference was taken into account, average cross-target strength was .09 $(S D=.05)$. Hence, in terms of normative measures of preexisting associative strength, cross-target connections were considerably stronger in this experiment than in previous experiments.

Procedure. The procedures were identical to those used in Experiment 3, with the exception that half of the subjects studied the directly related cross-target pairs prior to studying the target list, whereas the other half did not study these pairs.

\section{Results}

The probabilities of correct recall for subjects given prior study experience with the directly related cross- target pairings were .37 and .23 for cues with small and large sets. For subjects who studied only the target list, the comparable probabilities were .58 and .41 . As in Experiment 3 , substantial interference effects were present as a result of studying the cross-target pairs. Subjects who studied the cross-target pairs prior to the target list recalled $20 \%$ fewer items. However, set size effects were apparent regardless of whether these pairs were studied prior to the target list or not. Prior study significantly interfered with recall $\left[F(1,54)=16.80, M S_{\mathrm{e}}=.05\right]$, and cues with smaller sets were more likely to be recalled than those with larger sets $\left[F(1,54)=12.47, M S_{\mathrm{e}}=.04\right]$. Again, the interaction between cue set size and the prior study task was not significant $[F(1,54)=1.14]$. These findings, and those of Experiment 3, suggest that even when substantial cross-target interference effects are present in the associative cuing task, such effects appear to have little or no influence on the magnitude of the cue set size effect.

\section{GENERAL DISCUSSION}

The present paper was motivated by the discovery that eliminating normatively measured direct cross-target connections among pairs of related words does not eliminate indirect connections. Indirect connections are plentiful even when attempts are made to rid the list of such pesky links. As assessed by the multiplication-summation rule, most indirect connections tend to be relatively weak. For example, the test cue AREA had 16 connections to 8 other words appearing in the study list besides its filler, but the net cross-target connection strength came only to .018. However, there are exceptions. The cue FILTH had eight cross-target connections to five other targets, and its net cross-target strength averaged .17. Although crosstarget connections are generally weak, a few can be quite strong even when direct connections are ostensibly absent.

Such analyses suggest that potential interference effects arising from cross-target connections in the list cannot be simply ignored. To compound the problem, our analysis of past studies produced a moderate correlation $(r=.50)$ between cue set size and number of cross-target connections, suggesting that manipulations of cue set size were inadvertently confounded with number of crosstarget connections. Furthermore, prior work had shown that indirect connections involving the cue and the designated target facilitate recall (Nelson et al., 1997; Nelson, McKinney et al., 1998). At the outset of this research, it seemed plausible that the relationship between cue set size and recall was produced by indirect crosstarget connections rather than by set size. The main theoretical appeal of the cross-target explanation was that, at least for associative meaning, there would be no need to attribute such effects to the computation of a separate intersection involving the cue and its associates with the hypothesized implicit representation of the target. Instead, such effects could be attributed to preexisting connections involving the test cue and its associates with the words of the study list, connections that become more numerous as set size becomes larger. Indirect connec- 
tions to the target facilitate cued recall, and indirect connections to other list words may generate competitors from the list that interfere with such recall. This explanation for cue set size effects is more parsimonious because the computation of only a single intersection is required. However, this explanation does not extend to other types of cue set size effects. Taxonomic category names, rhymes, and word stems also produce cue set size effects (Nelson \& McEvoy, 1979), but such effects cannot be attributed to cross-target connections. In experiments using such cues, only a single instance of a particular taxonomic category, rhyme, or stem was represented in the study list, so cross-target connections occurring at the word level could not exist. Nevertheless, cuing with meaningfully related words offers no such protections, because indirect cross-target connections appear to be confounded naturally with cue set size. Hence, although PIER 2 may be adequate for explaining taxonomic and phonological information, we thought that it might not generalize to meaning.

In the present experiments, we attempted to forge a way around the correlation problem by letting the number of connections vary naturally while cross-target strength was held constant within each level of cue set size. The correlation between cross-target strength and cue set size for the materials used in these experiments was a scant $r=-.12$. Although set size and the numbers of crosstarget connections were correlated as usual $(r=.69)$, there was little or no relation between cross-target strength and set size. This equivalence is important because the predictions of PIER 2 are based on strength. With this procedure, the influences of cue set size and cross-target strength were evaluated in factorial designs using subjects as the basic unit of analysis. The relative influences of both the strength and the number of cross-target connections as well as other variables were also evaluated in regression analyses at the item level.

The results of this research are consistent with the conclusion that cue set size effects are not produced by cross-target connection strengths, but by set size itself. The combination of subject-based and item-based analyses suggests that cross-target strength in the absence of direct connection has only a small interfering effect at best and no noticeable influence on the magnitude of the cue set size effect. The negative effects of such connections are more apparent after subjects have studied the crosstarget pairings before studying and being tested on the target items. Such negative effects were apparent for indirectly related and for directly related cross-target pairings. However, despite the greater interference effect, cue set size effects were just as apparent when the interference was at its highest levels as when it was at its lowest levels. In each of the four experiments, the magnitude of the cue set size effect was uninfluenced by interference arising from cross-target connections that were strong enough to be measured by free association norms. The possibility that this effect might have been disrupted at more extreme levels of interference than those used here cannot be dis- missed. However, the manipulation of direct cross-target strength in Experiment 4 already goes far beyond the interference levels found in past associative cuing experiments in which measurable direct cross-target connections were eliminated during the list construction process. Hence, it seems clear that cues with larger sets of associates produce lower levels of recall not because such cues are more likely to be indirectly connected to other words in the list, but because such cues activate more associates in memory.

These findings have interesting implications for theory. First, the findings are consistent with expectations based on PIER 2 (Nelson, McKinney, et al., 1998). At the least, there was nothing in the data that rejects the basic assumption in this model that, in the associative cuing task, the presentation of the test cue initiates parallel searches. One search is directed toward the list memory produced as a result of conscious processing, and this search computes the intersection between the presented cue and this memory, presumably relying on the algorithms suggested in SAM (see, e.g., Raaijmakers \& Shiffrin, 1981). The other search is directed toward the hypothesized implicit representation of the target, and this search computes the intersection of the test cue and its associates with the residual activation of the target and its associates. Because the model also assumes that both searches contribute independently to recall in the associative cuing task, it can explain cross-target interference effects, cue set size effects, and the apparent additivity of these effects.

The second theoretical implication of the present findings is that cue set size effects apparently do not arise as the result of computing the intersection of the cue and its associates with list memory. That is, the findings reject what we have called the cross-target hypothesis as an explanation of cue set size effects. Humphreys et al. (1994) suggested this idea in describing their computationallevel theory, but it is important to note that it was linked only to the extralist cuing task and that it is not a central characteristic of their overall theory. Computationallevel theory can be implemented in a variety of waysso, for example, the matrix model should be able to handle the present findings with little difficulty (Humphreys et al., 1989).

The third theoretical implication of the present findings is related to the broader issue of how contextually based episodic information interacts with prior knowledge or what is sometimes called semantic memory (Tulving, 1983) or world knowledge (e.g., Kintsch, 1988). The evidence that prior knowledge can influence episodic performance is now substantial (e.g., Bahrick, 1970; Bransford \& Franks, 1971; Nelson, McKinney, et al., 1998; Nelson et al., 1992) as is the evidence indicating that this influence can be reduced by events occurring during the episode (e.g., Nelson \& McEvoy, 1979; Tulving \& Thomson, 1973). Prior knowledge is neither so omnipotent that it overwhelms the influence of context, nor is context so protective that it enfeebles the influence of prior knowledge. The evidence suggests that neither source of influence is invariably redundant with respect to the other, nor 
does either source seem to act in a mutually exclusive fashion. The important problem now lies in determining how this mutual and interactive influence should be captured and modeled. To this end we speculate that the more successful models will assume that the activation of prior knowledge and the encoding of episodic information contribute independently to memory performance. The assumption of independent contribution implies that, within a given task, some items will be recalled, recognized, or otherwise recovered as a result of recently encoded episodic information, some will be recovered as a result of the activation of what was already known, and some will be recovered as a result of their mutual influence. This assumption also implies that the contribution of one source of information or the other can be reduced or enhanced by changing test cues, test instructions, and tasks. What is most important, the independence assumption implies that the potential contributions of each source of information should be considered in attempting to model performance in any memory task.

\section{REFERENCES}

ANDERSON, J. R. (1983). A spreading activation theory of memory. Journal of Verbal Learning \& Verbal Behavior, 22, 261-295.

BaHRICK, H. P. (1970). Two-phase model for prompted recall. Psychological Review, 77, 215-222.

BransFord, J. D., \& Franks, J. J. (1971). The abstraction of linguistic ideas. Cognitive Psychology, 2, 331-350.

CROWDER, R. G. (1976). Principles of learning and memory. Hillsdale, NJ: Erlbaum.

Gillund, G., \& Shifrin, R. M. (1984). A retrieval model for both recognition and recall. Psychological Review, 91, 1-67.

Humphreys, M. S., Bain, J. D., \& PIKE, R. (1989). Different ways to cue a coherent memory system: A theory for episodic, semantic, and procedural tasks. Psychological Review, 96, 208-233.
Humphreys, M. S., Wiles, J., \& DenNis, S. (1994). Toward a theory of human memory: Data structures and access processes. Behavioral \& Brain Sciences, 17, 655-667.

KINTSCH, W. (1988). The role of knowledge in discourse comprehension: A construction-integration model. Psychological Review, 95, 163-182.

KuČEra, H., \& FranCIS, W. N. (1967). Computational analysis of present-day American English. Providence, RI: Brown University Press.

MARTIN, E. (1971). Verbal learning theory and independent retrieval phenomena. Psychological Review, 78, 314-332.

MCGEOCH, J. A. (1942). The psychology of human learning. New York: Longmans, Green.

Nelson, D. L., Bennett, D. J., \& Leibert, T. W. (1997). One step is not enough: Making better use of association norms to predict cued recall. Memory \& Cognition, 25, 785-796.

NeLson, D. L., \& MCEvoY, C. L. (1979). Encoding context and set size. Journal of Experimental Psychology: Human Learning \& Memory, 5, 292-314.

Nelson, D. L., McEvoy, C. L., \& Schreiber, T. A. (1998). The University of South Florida word association, rhyme, and word fragment norms. Available http://www.usf.edu/Free Association.

Nelson, D. L., MCKinney, V. M., Gee, N. R., \& Janczura, G. A. (1998). Interpreting the influence of implicitly activated memories on recall and recognition. Psychological Review, 105, 299-324.

Nelson, D. L., SCHREIBER, T. A., \& McEvoy, C. L. (1992). Processing implicit and explicit representations. Psychological Review, 99, 322-348.

RAaiJMakers, J. G. W., \& ShIFFrin, R. M. (1981). Search of associative memory. Psychological Review, 88, 93-134.

Tulving, E. (1983). Elements of episodic memory. New York: Oxford University Press.

Tulving, E., \& Thомson, D. M. (1973). Encoding specificity and retrieval processes in episodic memory. Psychological Review, 80, 352373.

UNDERWOOD, B. J. (1983). Attributes of memory. Glenview, IL: Scott, Foresman.

\section{NOTES}

1. PIER stands for Processing Implicit and Explicit Representations.

APPENDIX A

Lists Used in Experiments 1 and 3

\begin{tabular}{|c|c|c|c|c|}
\hline \multirow[b]{2}{*}{ Cue Set Size } & \multirow[b]{2}{*}{ Target Category } & \multirow[b]{2}{*}{ Test Cue } & \multicolumn{2}{|c|}{ Target } \\
\hline & & & High Interference & Low Interference \\
\hline \multicolumn{5}{|c|}{ List 1} \\
\hline \multirow[t]{12}{*}{ Small } & Critical & PALM & TREE & TREE \\
\hline & Filler & REST & RELAX & TIRED \\
\hline & Critical & SOCCER & FOOTBALL & FOOTBALL \\
\hline & Filler & STATUE & MARBLE & STONE \\
\hline & Critical & CARDBOARD & PAPER & PAPER \\
\hline & Filler & GRAB & BAG & SNATCH \\
\hline & Critical & THREAD & SEW & SEW \\
\hline & Filler & STRAIGHT & LINE & CROOKED \\
\hline & Critical & RODENT & MOUSE & MOUSE \\
\hline & Filler & SUPERMAN & FLY & HER \\
\hline & Critical & CANOE & PADDLE & PADDLE \\
\hline & Filler & CYLINDER & TUBE & CAN \\
\hline \multirow[t]{5}{*}{ Large } & Critical & AREA & PLACE & PLACE \\
\hline & Filler & EGYPT & PYRAMID & TEMPLE \\
\hline & Critical & MACHINE & WASHER & WASHER \\
\hline & Filler & SOCKET & WRENCH & PLUG \\
\hline & Critical & CASE & COURT & COURT \\
\hline
\end{tabular}


APPENDIX A (Continued)

\begin{tabular}{|c|c|c|c|c|}
\hline \multirow[b]{2}{*}{ Cue Set Size } & \multirow[b]{2}{*}{ Target Category } & \multirow[b]{2}{*}{ Test Cue } & \multicolumn{2}{|c|}{ Target } \\
\hline & & & High Interference & Low Interference \\
\hline & Filler & PROBABILITY & MATH & CHANCE \\
\hline & Critical & SUGGESTION & IDEA & IDEA \\
\hline & Filler & DEFINE & EXPLAIN & WORD \\
\hline & Critical & FOCUS & CONCENTRATE & CONCENTRATE \\
\hline & Filler & DEAF & BLIND & DUMB \\
\hline & Critical & SANDWICH & BREAD & BREAD \\
\hline & Filler & CRAVE & HUNGER & DESIRE \\
\hline \multicolumn{5}{|c|}{ List 2} \\
\hline \multirow[t]{12}{*}{ Small } & Critical & BARRACUDA & SHARK & SHARK \\
\hline & Filler & HELMET & MOTORCYCLE & HAT \\
\hline & Critical & SHINGLE & HOUSE & HOUSE \\
\hline & Filler & CURTAIN & DRAPES & ROD \\
\hline & Critical & MIRROR & IMAGE & IMAGE \\
\hline & Filler & SCORE & POINT & TEST \\
\hline & Critical & WINGS & FLY & FLY \\
\hline & Filler & DUCK & GOOSE & POND \\
\hline & Critical & DIG & DITCH & DITCH \\
\hline & Filler & SILK & WORM & SOFT \\
\hline & Critical & EVENING & MORNING & MORNING \\
\hline & Filler & RING & WEDDING & DIAMOND \\
\hline \multirow[t]{12}{*}{ Large } & Critical & INFORMATION & KNOWLEDGE & KNOWLEDGE \\
\hline & Filler & SPIRIT & SCHOOL & SOUL \\
\hline & Critical & CUT & BLOOD & BLOOD \\
\hline & Filler & TIE & NECK & KNOT \\
\hline & Critical & EXERCISE & SWEAT & SWEAT \\
\hline & Filler & STRAIGHT & NARROW & CROOKED \\
\hline & Critical & HARVEST & WHEAT & WHEAT \\
\hline & Filler & MASH & SQUASH & SMASH \\
\hline & Critical & FOREIGN & LANGUAGE & LANGUAGE \\
\hline & Filler & PARLIAMENT & ENGLAND & GOVERNMENT \\
\hline & Critical & CLAY & MOLD & MOLD \\
\hline & Filler & DRAW & PAINT & WRITE \\
\hline
\end{tabular}

APPENDIX B

Lists Used in Experiment 2

\begin{tabular}{|c|c|c|c|c|}
\hline \multirow[b]{2}{*}{ Cue Set Size } & \multirow[b]{2}{*}{ Target Category } & \multirow[b]{2}{*}{ Test Cue } & \multicolumn{2}{|c|}{ Target } \\
\hline & & & High Interference & Low Interference \\
\hline \multicolumn{5}{|c|}{ List 1} \\
\hline \multirow[t]{16}{*}{ Small } & Critical & BUBBLE & BATH & BATH \\
\hline & Filler & BLOW, BELOW & BALLOON & BASEMENT \\
\hline & Critical & CHIMPANZEE & APE & APE \\
\hline & Filler & AFRICA, KLEENEX & JUNGLE & WIPE \\
\hline & Critical & DIFFICULTY & TROUBLE & TROUBLE \\
\hline & Filler & COMFORTABLE, MOUSSE & EASE & HAIRSPRAY \\
\hline & Critical & ENTRANCE & DOORWAY & DOORWAY \\
\hline & Filler & PAIN, PAIR & THRESHOLD & GLOVES \\
\hline & Critical & MOLECULE & CHEMISTRY & CHEMISTRY \\
\hline & Filler & OXYGEN, PUBLISHER & ELEMENT & NEWSPAPER \\
\hline & Critical & CORK & CHAMPAGNE & CHAMPAGNE \\
\hline & Filler & BEVERAGE, PUN & BEER & WORD \\
\hline & Critical & REEF & BEACH & $\mathrm{BEACH}$ \\
\hline & Filler & WHALE, SMUDGE & SHARK & STAIN \\
\hline & Critical & TROT & JOG & JOG \\
\hline & Filler & STRAIN, TUMBLE & SWEAT & GYMNASTICS \\
\hline \multirow[t]{2}{*}{ Large } & Critical & BUTTERFLY & BIRD & BIRD \\
\hline & Filler & BROTH, AMBULANCE & CHICKEN & SIREN \\
\hline
\end{tabular}


APPENDIX B (Continued)

\begin{tabular}{|c|c|c|c|c|}
\hline \multirow[b]{2}{*}{ Cue Set Size } & \multirow[b]{2}{*}{ Target Category } & \multirow[b]{2}{*}{ Test Cue } & \multicolumn{2}{|c|}{ Target } \\
\hline & & & High Interference & Low Interference \\
\hline & Critical & DECENCY & RESPECT & RESPECT \\
\hline & Filler & CONFIDENCE, AWARD & PRIDE & ACHIEVEMENT \\
\hline & Critical & LIZARD & FROG & FROG \\
\hline & Filler & TOAD, COUNSEL & WART & ADVISE \\
\hline & Critical & MARBLE & ROUND & ROUND \\
\hline & Filler & $\mathrm{COACH}$, OATS & FOOTBALL & OATMEAL \\
\hline & Critical & MOVIE & ENTERTAINMENT & ENTERTAINMENT \\
\hline & Filler & PRODUCTION, BOG & PERFORMANCE & SWAMP \\
\hline & Critical & NEIGHBORHOOD & CHILDREN & CHILDREN \\
\hline & Filler & DIVORCE, TRAVEL & PARENTS & EUROPE \\
\hline & Critical & PLAID & PATTERN & PATTERN \\
\hline & Filler & TUXEDO, TRANSPLANT & SUIT & REPLACE \\
\hline & Critical & PLAN & STRATEGY & STRATEGY \\
\hline & Filler & WEST, STORAGE & DIRECTION & JUNK \\
\hline \multirow{17}{*}{ Small } & & List 2 & & \\
\hline & Critical & CANOE & PADDLE & PADDLE \\
\hline & Filler & PELICAN, BALD & FISH & HAIRY \\
\hline & Critical & ASTRONOMY & ASTROLOGY & ASTROLOGY \\
\hline & Filler & LIBRARY, BUCKLE & STUDY & STRAP \\
\hline & Critical & FILTH & GRIME & GRIME \\
\hline & Filler & DIRTY, CELERY & SCUM & STALK \\
\hline & Critical & FORK & EAT & EAT \\
\hline & Filler & TILE, CEMENT & KITCHEN & CONCRETE \\
\hline & Critical & GIRAFFE & ELEPHANT & ELEPHANT \\
\hline & Filler & TROPICAL, CYLINDER & JUNGLE & TUBE \\
\hline & Critical & SON & BROTHER & BROTHER \\
\hline & Filler & PARENTS, HAT & FAMILY & RACK \\
\hline & Critical & SPOOL & YARN & YARN \\
\hline & Filler & TUG, HOE & ROPE & FARMER \\
\hline & Critical & VIOLET & ROSE & ROSE \\
\hline & Filler & TAXI, TORCH & YELLOW & BURN \\
\hline \multirow[t]{16}{*}{ Large } & Critical & CHEER & FOOTBALL & FOOTBALL \\
\hline & Filler & POKER, ADORN & PLAYER & DECORATE \\
\hline & Critical & EASE & COMFORT & COMFORT \\
\hline & Filler & STRAIN, BRUISE & STRESS & SCAR \\
\hline & Critical & FACTORY & INDUSTRY & INDUSTRY \\
\hline & Filler & FEDERAL, MANNER & UNION & BEHAVIOR \\
\hline & Critical & FORM & MOLD & MOLD \\
\hline & Filler & SCULPTURE, CHAOS & CLAY & ANARCHY \\
\hline & Critical & GRAVE & TOMBSTONE & TOMBSTONE \\
\hline & Filler & WART, LAUNCH & MOLE & MISSILE \\
\hline & Critical & LIMIT & MAXIMUM & MAXIMUM \\
\hline & Filler & SCALES, WIRE & MEASURE & ELECTRIC \\
\hline & Critical & PRAISE & RECOMMENDATION & RECOMMENDATION \\
\hline & Filler & OPINION, POTENTIAL & BELIEF & LACK \\
\hline & Critical & SINGER & MICROPHONE & MICROPHONE \\
\hline & Filler & SOUND, PACKAGE & SPEAKER & DELIVER \\
\hline
\end{tabular}


APPENDIX C

Lists Used in Experiment 4

\begin{tabular}{|c|c|c|c|c|c|}
\hline \multirow[b]{2}{*}{ Cue Set Size } & \multirow[b]{2}{*}{ Category } & \multicolumn{2}{|c|}{ List 1} & \multicolumn{2}{|c|}{ List 2} \\
\hline & & Test Cue & Target & Test Cue & Target \\
\hline \multirow[t]{12}{*}{ Small } & Critical & PALM & TREE & BARRACUDA & SHARK \\
\hline & Filler & SHELL & $\mathrm{BEACH}$ & CORAL & OCEAN \\
\hline & Critical & SOCCER & FOOTBALL & SHINGLE & HOUSE \\
\hline & Filler & TOYS & PLAY & CURTAIN & WINDOW \\
\hline & Critical & CARDBOARD & PAPER & MIRROR & IMAGE \\
\hline & Filler & ВООТН & TABLE & MASK & FACE \\
\hline & Critical & THREAD & SEW & WINGS & FLY \\
\hline & Filler & KITE & STRING & DEVIL & ANGEL \\
\hline & Critical & RODENT & MOUSE & DIG & DITCH \\
\hline & Filler & PEST & $\mathrm{ROACH}$ & CAMPING & GROUND \\
\hline & Critical & CANOE & PADDLE & EVENING & MORNING \\
\hline & Filler & DIVE & SWIM & ARRIVE & LATE \\
\hline \multirow[t]{12}{*}{ Large } & Critical & AREA & PLACE & INFORMATION & KNOWLEDGE \\
\hline & Filler & CONTINENT & LAND & DAILY & NEWS \\
\hline & Critical & MACHINE & WASHER & CUT & BLOOD \\
\hline & Filler & WHEEL & CAR & $\mathrm{ACHE}$ & HURT \\
\hline & Critical & CASE & COURT & EXERCISE & SWEAT \\
\hline & Filler & DOCTOR & LAWYER & LEAN & SKINNY \\
\hline & Critical & SUGGESTION & IDEA & HARVEST & WHEAT \\
\hline & Filler & DESCRIBE & TELL & FRUIT & VEGETABLES \\
\hline & Critical & FOCUS & CONCENTRATE & FOREIGN & LANGUAGE \\
\hline & Filler & INSPECT & LOOK & DISTANCE & FAR \\
\hline & Critical & SANDWICH & BREAD & CLAY & MOLD \\
\hline & Filler & TOMATO & LETTUCE & CREATIVE & ART \\
\hline
\end{tabular}

(Manuscript received November 13, 1997;

revision accepted for publication May 22, 1998.) 